\title{
What contributes to long-term quality of life in breast cancer patients who are undergoing surgery? Results of a multidimensional study
}

\author{
Victoria Wittmann $^{1}{ }^{1} \cdot$ Melinda Látos $^{1} \cdot$ Zoltán Horváth $^{1} \cdot$ Zsolt Simonka $^{1}$. \\ Attila Paszt $^{1}$ - György Lázár ${ }^{1}$ - Márta Csabai ${ }^{2}$
}

Accepted: 24 March 2017

(C) Springer International Publishing Switzerland 2017

\begin{abstract}
Purpose This study aims to examine the key determinants of long-term quality of life in breast cancer patients who are undergoing surgery using a multidimensional approach and taking into account preoperative and post-operative psychological characteristics such as anxiety, depression, posttraumatic growth, body image, and physical activity as well as medical parameters.

Methods The study involved 63 breast cancer patients from the Department of Surgery at the University of Szeged. Assessments occurred 1 day before surgery as well as 3 days and 18 months after surgery using the Spielberger State and Trait Anxiety Inventory (STAI), Beck's Depression Inventory (BDI), Functional Assessment of Cancer Therapy-Breast Cancer Scale (FACT-B), Posttraumatic Growth Inventory (PTGI) and Breast Impact of Treatment Scale (BITS). Data relating to physical activity, medical parameters and sociodemographic characteristics were also collected.

Results The level of depression did not change over time. State anxiety decreased 18 months after the surgery compared to before the surgery; however, there was a greater decrease immediately after the surgery and then anxiety increased again 18 months later. Trait anxiety was associated with quality of life, posttraumatic growth and body image. Posttraumatic growth and the level of depression
\end{abstract}

Victoria Wittmann

victoriawittmann1@gmail.com

1 Department of Surgery, Faculty of Medicine, University of Szeged, Szőkefalvi-Nagy B. Street 6, Szeged H 6720, Hungary

2 Psychology Institute, University of Szeged, Egyetem Street 22, Szeged H 6722, Hungary were found to be possible contributing factors to the increase in long-term quality of life.

Conclusions The results show that the timely detection and proper management of psychological distress and the enhancement of posttraumatic growth are of great value, as they might be important contributing factors to long-term quality of life in breast cancer patients.

Keywords Breast cancer - Psychological distress . Quality of life $\cdot$ Body image $\cdot$ Posttraumatic growth

\section{Introduction}

The traumatic nature of the diagnosis and the painful surgical procedures often lead to a series of psychological problems among cancer patients. An estimated 1.1 million women are diagnosed with breast cancer worldwide, and 410,000 die of the disease each year [1]. Meta-analyses suggest that stress-related psychosocial factors and lower health-related quality of life (QoL) are associated with poorer survival among people with breast cancer [2]. Depression and anxiety are typical responses after diagnosis and during the treatment phase, making psychological screening and intervention extremely relevant [3].

Furthermore, the level of psychological distress is usually higher before surgery at the beginning of the disease $[4,5]$. According to Ho et al. [6], patients who are in treatment report higher depression and anxiety than patients who are in post-treatment, which supports the increased importance of psychological interventions not only after treatment but also in the early stage of treatment. QoL is an important outcome measure in all patients with breast cancer due to the complexity of the disease, with emotional, 
functional, physical, social and sexual factors all playing a role $[3,7-9]$.

Posttraumatic growth (PTG) is defined as perceived positive changes in previous levels of functioning following a traumatic life event $[10,11]$. Following a diagnosis of breast cancer, many women report PTG in a variety of life domains (e.g. recognition of new possibilities in one's life, a greater sense of personal strength, and spiritual development) [12-15]. However, it is unclear whether PTG is associated with a higher level of distress or enhanced QoL among cancer survivors, as researchers have reported positive and negative associations and inconclusive results [15-22].

The often traumatic and disfiguring nature of breast cancer surgery can also lead to a series of psychological problems relating to body image, sexuality and femininity [23-25]. Body change stress refers to subjective psychological stress that accompanies women's negative and distressing feelings, emotions, thoughts and behaviours originating from and connected to breast cancer and/or breast surgeries [23]. Body change stress manifests as stress symptoms that are similar to those found in traumas, including re-experiencing (e.g. feeling upset with reminders of breast change), avoidance (e.g. attempts to limit the exposure of the body to oneself or others) and arousal symptoms (e.g. irritability) [23].

Whereas many of the symptoms that are associated with breast cancer and its treatment can last for several months or even years after treatment is complete, studies have shown that regular physical activity is beneficial in reducing and relieving cancer-related symptoms and improving QoL in cancer patients [26-29]. However, few studies have focused on the connection between QoL and PTG in relation to physical activity and body image using a longitudinal study design by observing changes in behaviour prior to and long after the operation [30-35].

\section{Aims and research questions}

Our primary goal was to gain a more complete understanding of the key determinants of long-term QoL in breast cancer patients who are undergoing surgery. Given that little empirical research has been done to investigate this question using a multidimensional approach, we surveyed a group of women who had been living with this disease for 18 months using a prospective, multidimensional study design, taking into account pre- and post-operative psychological characteristics such as anxiety, depression, posttraumatic growth, body image, and physical activity as well as medical parameters. An additional goal was for the potentially positive results of this study to serve as a clear theoretical basis for our intervention studies that we plan to conduct with breast cancer patients who are undergoing surgery.

The following served as the research questions of the study:

1. What are the characteristic correlational patterns of the contributing factors that influence the long-term QoL of breast cancer patients?

2. Eighteen months after surgery, how do emotional factors and QoL change in breast cancer patients?

We hypothesized that an enhanced QoL would be associated with positive mood factors, greater PTG and a higher level of physical activity.

\section{Methods}

\section{Study design and sample}

All the materials that were used in this study were approved by the Regional and Institutional Human Medical Biological Research Ethics Committee. Prior to their surgery for breast cancer, the patients were assessed in the Department of Surgery at the University of Szeged. Each patient was provided with comprehensive information regarding the study and signed an informed consent form. The final sample comprised 63 female patients. The inclusion criteria were: (i) breast cancer that was confirmed by histological examination, (ii) ability to complete the necessary questionnaires, and (iii) ability to understand the objective of the study and provide informed consent. The exclusion criteria were (i) secondary breast cancer, (ii) psychiatric disorder(s) and (iii) male sex. Psychological assessments were conducted by a trained health psychologist who did not have access to medical data about the patients. The data were assessed at three time points: 1 day before surgery (T1), 3 days after surgery (T2) and 18 months after surgery (T3).

\section{Study measures}

The Spielberger State and Trait Anxiety Inventory (STAI-S; STAI-T) was administered to measure the level of anxiety before and after surgery [36]. Both the scales comprise 20 items, with responses ranging from 1 (not at all) to 4 (very much so). Total scores range from 20 to 80 , with a higher number indicating a higher level of anxiety. In the STAI-S, a mean score above 50 indicates severe state anxiety. The STAI-S was administered 1 day before surgery and both 3 days and 18 months after surgery. In the STAI-T, a mean score $<48$ indicates no trait anxiety, a mean score of 48-52 indicates minor trait anxiety, and 
a mean score $>52$ indicates severe trait anxiety [37]. The STAI-T was administered 1 day before surgery. The Hungarian versions of the STAI-S and STAI-T have good reliability [38].

Beck's Depression Inventory (BDI) was used to assess the severity of depressive symptoms [39]. The BDI was administered at two time points: before surgery and 18 months after surgery. All the parts include four statements that describe feelings in recent weeks. The responses range from 0 to 3 . Total scores range from 0 to 84 , with a higher number indicating a higher level of depression. The lowest total score was 0 , whereas the highest score was 84 .

Using the standard cut-off scores, a score of 0-9 indicates minimal depression; 10-18 indicates mild depression; 19-25 indicates moderate depression and $>25$ indicates severe depression $[39,40]$. The reliability of the scale is adequate (Cronbach's alpha $=0.86)$ [41].

The FACT-Breast (FACT-B) was used to assess QoL, as it was designed specifically for breast cancer patients [42]. Patients are asked to respond to statements regarding the status of their breast as well as their emotional, functional, physical, and social well-being. Patients choose the number that corresponds with how true each statement has been for them during the past 7 days. Answers are scored using a Likert-type scale. The FACT-B was administered 1 day before and 18 months after surgery. The total FACTB score (including all the subscales) ranges from 0 to 144 , with a higher number indicating a more favourable QoL. The subscales evaluate breast well-being (score range 0-36), emotional well-being (score range 0-24), functional well-being (score range 0-28), physical well-being (score range 0-28), and social well-being (score range 0-28). The reliability of the FACT-B in general is high (Cronbach's alpha $=0.9)$ [42]. The Cronbach's alpha of the global QoL scale in this study was 0.73 before surgery and 0.79 after surgery.

We employed the Posttraumatic Growth Inventory (PTGI) 18 months after surgery, which was designed to assess positive outcomes following a struggle with highly challenging life circumstances [43]. The questionnaire comprises five subscales (relating to others, new possibilities, personal strength, spiritual change, and appreciation of life) and yields a total posttraumatic growth score (range 0-105). The higher the total score is, the greater the PTG is. The Hungarian version of the PTGI showed good reliability (Cronbach's alpha $=0.898$ ) [43].

To measure stress from body change related to breast cancer surgery, the Breast Impact of Treatment Scale was used (total score range 0-75) 18 months after surgery [44]. The subscales evaluate intrusive thoughts and level of avoidance. The higher the total score is, the higher the level of body change stress is. The BITS was found to be a good screening tool in general and has shown high reliability in measuring body change stress $($ Cronbach's alpha $=0.91$ ) [44].

\section{Sociodemographic factors and physical activity}

The sociodemographic background factors included age, marital status, number of children and level of education. Physical activity was also measured, with questions addressing the type and number of hours of physical activity per week. Similar to the study by [45], we measured physical activity using open-ended questions [45].

The questions were as follows:

1. Since your diagnosis, has exercise/sport been part of your life?

2. If so, what type of exercise/sport do you do?

3. How many hours of exercise/sport do you do weekly?

We considered patients' physically active if they engaged in at least $1 \mathrm{~h}$ of physical activity per week. In our study, physical activity was described as specific physical activities (e.g. running, yoga). Other physical activities (e.g. gardening) were not counted as specific physical activities.

\section{Medical parameters of patients}

The medical parameters that were examined in the study were the side, size and grade of the tumour; type of neoadjuvant therapy; and type of surgery (excision/mastectomy).

\section{Statistical analyses}

The data were analysed using IBM SPSS 20.0 for Windows. Quantitative variables were described using the mean and standard deviation. Qualitative variables such as the sociodemographic characteristics were described using the percentage. To reveal the pattern of the relationships among the variables, Spearman's and Pearson's correlations were used. The differences between the variables at different time points were calculated using the paired-samples $t$ test, Wilcoxon test and repeatedmeasures analysis of variance (rANOVA). Group comparisons were performed with the Mann-Whitney U test. Physical activity was measured as a dichotomous variable (physically active/not physically active). We also asked the patients to report their mean number of hours of physical activity per week. The FACT-B, BITS, and PTGI subscale scores were compared in different subgroups of patients, depending on the sociodemographic, psychological and medical variables. Multiple linear regression (stepwise method) was performed to identify the potential predictors of long-term QoL. The FACT-B scale (18 months after surgery) served as the dependent 
variable. The independent variables that were entered into the regression analysis were physical activity, and all the psychological variables were measured in our study, which had been found to have a long-term influence on QoL in breast cancer patients undergoing surgery in previous studies [30-35]. These psychological variables were depression, state and trait anxiety, PTG and its subscales, stress relating to body change and its subscales. The results were considered statistically significant when the $p$ value was less than 0.05 .

\section{Results}

\section{Sociodemographic and medical characteristics}

The 63 breast cancer patients' mean age was 56.1 years $(\mathrm{SD}=11.92)$. In addition, $52.4 \%$ of them had a secondary school qualification, and most of them were married $(73 \%)$. Nearly $75 \%$ of them had an excision, and the mean tumour size was $21.61 \mathrm{~mm}(\mathrm{SD}=21)$. Only five of the patients received neoadjuvant treatment, and $59.7 \%$ of them were physically active (Table 1 ). No significant associations were found between the type of surgery and psychological factors $(p>0.05)$.

\section{The influence of sociodemographic factors}

No significant associations were found between trait and state anxiety before and after the operation and marital status $(p>0.05)$, age $(p>0.05)$, number of children $(p>0.05)$ and education level $(p>0.05)$. No significant correlations were found between the depression scales and marital status $(p>0.05)$, age $(p>0.05)$, number of children $(p>0.05)$ and education level $(p>0.05)$.

However, age was significantly correlated with the PTGI $(r=-0.275, p<0.05)$ and FACT-B $(r=-0.276$, $p<0.05)$ scores 18 months after the operation. Education level was significantly associated with the FACTB $[\mathrm{H}(2)=8.175, p<0.05]$ and PTGI $[\mathrm{H}(2)=6.292$, $p<0.05$ ] scores 18 months after the operation. Patients with a lower education level had a lower FACT-B score (89 vs. 113.8) and PTGI score (54.6 vs. 74.8$)$ than patients with a university qualification 18 months after the operation.

Marital status was associated with the FACT-B social well-being factor $(U=184.5, Z=-2.167, p=0.03)$. Married patients had a higher social well-being factor score before the operation compared to unmarried patients (30.01 vs. 20.04). The number of children was not correlated with the PTGI and FACT-B scores $(p>0.05)$.
Table 1 Sociodemographic and medical characteristics $(N=63)$

\begin{tabular}{|c|c|}
\hline Characteristics & \\
\hline Mean age (SD) & $56.1(11.92)$ \\
\hline \multicolumn{2}{|l|}{ Marital status $N(\%)$} \\
\hline Married & $46(73)$ \\
\hline Not married & $17(27)$ \\
\hline \multicolumn{2}{|l|}{ Educational level $N(\%)$} \\
\hline Primary qualification & $11(17.5)$ \\
\hline Higher secondary qualification & $33(52.4)$ \\
\hline University qualification & $19(30.1)$ \\
\hline Number of children (Mean, SD) & $2.03(0.96)$ \\
\hline \multicolumn{2}{|l|}{ Type of surgery $N(\%)$} \\
\hline Excision & $47(74.6)$ \\
\hline Mastectomy & $16(25.4)$ \\
\hline \multicolumn{2}{|l|}{ Grade $N(\%)$} \\
\hline I & $10(19.2)$ \\
\hline II & $26(50)$ \\
\hline III & $16(30.8)$ \\
\hline Tumour size (Mean, SD) & $21.61(21)$ \\
\hline \multicolumn{2}{|l|}{ Neoadjuvant treatment $N(\%)$} \\
\hline Yes & $5(8.1)$ \\
\hline No & $57(91.9)$ \\
\hline \multicolumn{2}{|l|}{ Side of tumour $N(\%)$} \\
\hline Right & $29(46)$ \\
\hline Left & $33(52.4)$ \\
\hline \multicolumn{2}{|l|}{ Physical activity } \\
\hline Yes & $37(59.7)$ \\
\hline No & $25(40.3)$ \\
\hline
\end{tabular}

QoL, anxiety, depression, PTG and body change stress

The mean scores on QoL, anxiety, depression, PTG and body change stress (at all three time points) are listed in Table 2. Compared to the cut-off scores, the mean scores on trait anxiety and depression indicated relatively low but stable levels of distress at all relevant time points. The BDI mean score did not change significantly over time (Table 2). State anxiety was significantly higher before the operation than 3 days after the operation (Table 2). Furthermore, state anxiety was significantly higher 18 months after the operation than 3 days after the operation (Table 2). The FACT-B mean score did not change significantly over time (Table 2). Functional well-being and physical well-being changed significantly from their level pre-surgery to their level 18 months post-surgery (Table 2). The patients reported better functional wellbeing and physical well-being 18 months after the operation compared to pre-operation (Table 2). 
Table 2 QoL, anxiety, depression, PTG and body change stress in the study sample $(N=63)$

\begin{tabular}{|c|c|c|c|c|}
\hline & Baseline mean (SD) & 3 days mean (SD) & 18 months mean (SD) & $\begin{array}{l}\text { Baseline-18 } \\
\text { months } p \\
\text { value }\end{array}$ \\
\hline \multicolumn{5}{|l|}{ FACT-B } \\
\hline Emotional well-being & $18.35(4.33)$ & & $19.22(4.48)$ & $0.265^{\mathrm{a}}$ \\
\hline Functional well-being & $17.45(6.02)$ & & $19.31(5.44)$ & $0.054^{a}$ \\
\hline Physical well-being & $20.33(4.62)$ & & $23.87(4.74)$ & $0.000^{\mathrm{a}}$ \\
\hline Social well-being & $20.39(5.67)$ & & $20.11(5.96)$ & $0.563^{\mathrm{a}}$ \\
\hline Breast well-being & $23.94(5.84)$ & & $23.96(7.33)$ & $0.727^{\mathrm{a}}$ \\
\hline FACT-B total & $99.30(19.30)$ & & $104.57(23.66)$ & $0.067^{\mathrm{a}}$ \\
\hline BDI & $8.36(7.07)$ & & $8.81(7.23)$ & $0.589^{\mathrm{c}}$ \\
\hline STAI-T & $44.90(9.76)$ & & & \\
\hline STAI-S & $51.46(12.08)$ & $39.72(9.55)$ & $41.52(12.25)$ & $\mathbf{0 . 0 0 0}^{b}$ \\
\hline \multicolumn{5}{|l|}{ PTGI } \\
\hline Relating to others & & & $20.26(9.50)$ & \\
\hline New possibilities & & & $12.83(7.40)$ & \\
\hline Personal strength & & & $12.21(7.36)$ & \\
\hline Spiritual change & & & $4.27(3.28)$ & \\
\hline Appreciation of life & & & $10(4.38)$ & \\
\hline PTGI total & & & $59.5(27.66)$ & \\
\hline BITS & & & $8.81(7.23)$ & \\
\hline Intrusive thoughts & & & $13.52(15.39)$ & \\
\hline Level of avoidance & & & $4.84(4.83)$ & \\
\hline BITS total & & & $18.37(19.84)$ & \\
\hline
\end{tabular}

Bold values indicate the significant $p$ values between $(p=0.00$ and $p=0.05$ )

$S D$ standard deviation

${ }^{a}$ Wilcoxon test

${ }^{\mathrm{b}}$ rAnova

${ }^{\mathrm{c}}$ Paired sample $t$ test

\section{Correlations between QoL and anxiety, depression, PTG and body change stress}

Depression 1 day before and 18 months after surgery had a significant positive correlation with state and trait anxiety (Table 3). QoL before surgery and the subscales of QoL (except social well-being) before surgery had a significant negative correlation with depression and anxiety (Table 3 ). QoL 18 months after surgery and the subscales of QoL 18 months after surgery had a significant negative correlation with depression and trait anxiety (Table 3 ). The statistical measures indicated that PTG had a significant negative correlation with depression and trait anxiety 18 months after surgery (Table 3). A significant positive correlation was found between body change stress and both depression and trait anxiety 18 months after surgery (Table 3 ).

There was a significant association between QoL 18 months after surgery and PTG (Table 3). The statistical measures indicated significant positive correlations between QoL 18 months after surgery and the following PTG subscales: relating to others, new possibilities, personal strength, and spiritual change (Table 3). A negative association was found between body change stress and both QoL 18 months after surgery and the QoL subscales (emotional well-being, physical well-being and breast wellbeing) 18 months after the operation (Table 3). There was no significant association between body change stress and PTG (Table 3).

\section{Associations between physical activity and mood factors, QoL, PTG and body change stress}

In our study, mean number of hours of physical activity per week was measured $(\mathrm{M}=3.02, \mathrm{SD}=2.19)$. The results of statistical analyses showed no significant association between physical activity and psychological distress or QoL before the operation (Table 4). However, there was a significant association between physical activity and both depression and state anxiety 18 months after the operation (Table 4). Patients who engaged in physical activity had lower mean scores on depression and state anxiety 18 months after the surgery (Table 4). 
Table 3 Correlation between QoL and anxiety, depression, PTG and body change stress $(N=63)$

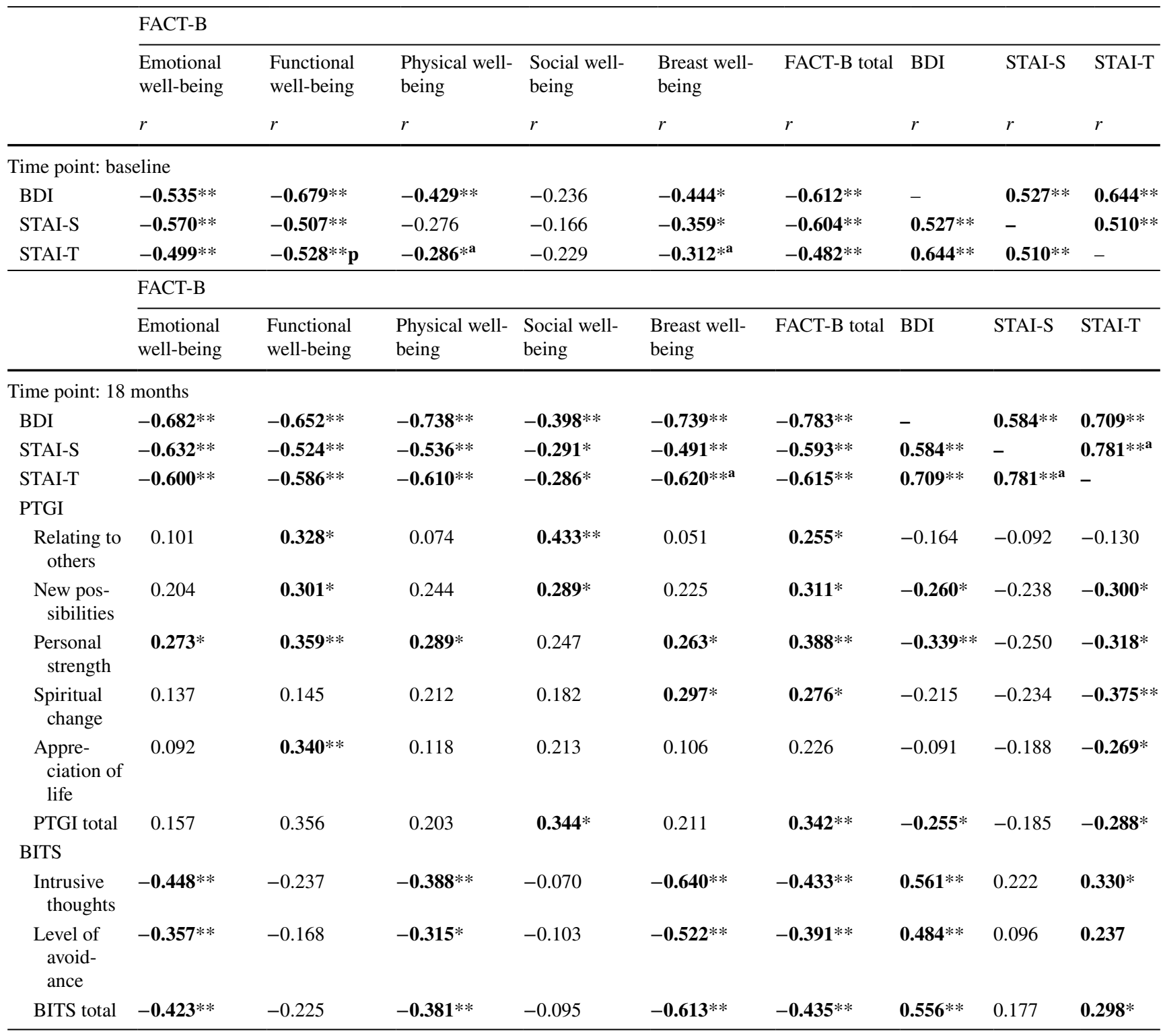

Bold values indicate the significant $p$ values between $(p=0.00$ and $p=0.05$ )

$r=$ Spearman correlation coefficient except

${ }^{*} p<0.05, * * p<0.01$

${ }^{\mathrm{a}}$ Pearson correlation coefficient

There was a significant relationship between QoL 18 months after the operation and physical activity among the breast cancer patients (Table 4). Patients who engaged in physical activity had higher scores on the FACT-B scale as well as the functional well-being, physical well-being and breast well-being subscales 18 months after the operation (Table 4).

There was a significant association between PTG and physical activity. Patients who engaged in physical activity had higher scores on the new possibilities and personal strength subscales (Table 4). No significant association was found between body change stress and physical activity (Table 4).

\section{Possible predictive factors of QoL: linear regression analysis}

In the further investigation, a linear regression analysis was used to identify factors that contribute to better QoL (dependent variable). There were significant interactions with variables and QoL 18 months after the operation. The linear regression identified two main potential 
Table 4 Associations between physical activity and mood factors, QoL, PTG and body change stress $(N=63)$

\begin{tabular}{|c|c|c|c|c|}
\hline \multirow[t]{2}{*}{ Time point: baseline } & Physically active $(N=37)$ & $\begin{array}{l}\text { Physically not } \\
\text { active }(N=24)\end{array}$ & $\begin{array}{l}\text { Mann-Whitney } \\
\text { Test Z }\end{array}$ & $p$ \\
\hline & $\mathrm{M}(\mathrm{SD})$ & \multicolumn{3}{|l|}{$\mathrm{M}(\mathrm{SD})$} \\
\hline BDI & $8.80(1.35)$ & $9.87(2.28)$ & -0.611 & 0.541 \\
\hline STAI-S & $50.50(2.58)$ & $49.56(2.53)$ & -0.765 & 0.444 \\
\hline STAI-T & $41.80(2.04)$ & $47.93(3.06)$ & -1.580 & 0.114 \\
\hline \multicolumn{5}{|l|}{ FACT-B } \\
\hline Emotional well-being & $18.61(0.76)$ & $18.93(0.78)$ & -0.293 & 0.770 \\
\hline Functional well-being & $18.76(1.01)$ & $15.50(1.62)$ & -1.113 & 0.266 \\
\hline Physical well-being & $19.88(0.92)$ & $20.81(1.04)$ & -0.765 & 0.444 \\
\hline Social well-being & $21.03(0.86)$ & $21.68(0.92)$ & -0.924 & 0.355 \\
\hline Breast well-being & $24.26(1.20)$ & $24.87(1.41)$ & -0.469 & 0.693 \\
\hline FACT-B total & $102.57(3.46)$ & $101.81(4.13)$ & -1.035 & 0.301 \\
\hline \multicolumn{5}{|l|}{ Time point: 18 months } \\
\hline BDI & $7.15(1.22)$ & $12.62(2.25)$ & -2.546 & 0.010 \\
\hline STAI-S & 37 (1.89) & $47.87(3.73)$ & -2.327 & $\mathbf{0 . 0 2 0}$ \\
\hline \multicolumn{5}{|l|}{ FACT-B } \\
\hline Emotional well-being & $20.07(0.77)$ & $17.43(1.40)$ & -1.040 & 0.298 \\
\hline Functional well-being & $21.15(0.91)$ & $16.00(1.37)$ & -2.576 & 0.010 \\
\hline Physical well-being & $24.46(0.91)$ & $22.12(1.32)$ & -2.288 & 0.022 \\
\hline Social well-being & $20.73(1.21)$ & $16.81(1.57)$ & -1.702 & 0.089 \\
\hline Breast well-being & $26.46(1.26)$ & $21.81(1.93)$ & -2.670 & 0.008 \\
\hline FACT-B total & $112.8(3.80)$ & $94.18(5.86)$ & -3.244 & 0.001 \\
\hline \multicolumn{5}{|l|}{ PTGI } \\
\hline Relating to others & $20.46(1.82)$ & $17.81(2.25)$ & -0.906 & 0.365 \\
\hline New possibilities & $13.88(1.42)$ & $9.62(1.66)$ & -2.187 & 0.029 \\
\hline Personal strength & $13.88(1.61)$ & $9.12(1.72)$ & -2.367 & $\mathbf{0 . 0 1 8}$ \\
\hline Spiritual change & $4.84(0.65)$ & $3.75(0.86)$ & -1.735 & 0.083 \\
\hline Appreciation of life & $10.53(0.78)$ & $9.62(1.17)$ & -0.941 & 0.347 \\
\hline PTGI total & $63.61(5.16)$ & $49.93(6.79)$ & -1.818 & 0.069 \\
\hline \multicolumn{5}{|l|}{ BITS } \\
\hline Intrusive thoughts & $11.38(2.71)$ & $16(4.62)$ & -1.083 & 0.279 \\
\hline Level of avoidance & $4.38(0.91)$ & $5.43(1.36)$ & -1.353 & 0.176 \\
\hline BITS total & $15.76(3.56)$ & $21.43(5.89)$ & -1.206 & 0.228 \\
\hline
\end{tabular}

Bold values indicate the significant $p$ values between $(p=0.00$ and $p=0.05)$ predictors. The resulting model was statistically significant $(p<0.001)$, and $\mathrm{R}^{2}$ was 0.739 . The BDI (18 months after the operation) variable $(\beta=-0.75)$ and PTGI variable $(\beta=0.22)$ were identified as significant predictors of QoL 18 months after the operation (Table 5).

\section{Discussion}

The aim of this study was to identify and interpret the interrelationships among the most important factors that influence long-term QoL in breast cancer patients who are undergoing surgery and to create a clear theoretical basis
Table 5 Possible predictive factors of QoL: linear regression analysis (method $=$ stepwise; $N=63$ )

\begin{tabular}{|c|c|c|c|c|c|c|c|}
\hline & $\beta$ & B & Standard error B & $\mathrm{t}$ & $\mathrm{F}$ & $\mathrm{R}^{2}$ & Adjusted $\mathrm{R}^{2}$ \\
\hline Model 1 & & & & & $76.643 * *$ & 0.739 & 0.730 \\
\hline BDI (T3) & -0.759 & -2.204 & 0.213 & -10.356 & & & \\
\hline PTGI total & 0.229 & 0.179 & 0.057 & 3.131 & & & \\
\hline
\end{tabular}

Bold values indicate the significant $p$ values between $(p=0.00$ and $p=0.05$ )

** $p<0.0 ; T 3$ time point $3=18$ months after the operation 
for our intervention studies that we plan to conduct with breast cancer patients who are undergoing surgery.

This study showed that patients had relatively low levels of depression and trait and state anxiety as well as high QoL before the surgery. There was no change in the level of depression before the surgery and 18 months after it. In our study, state anxiety decreased from pre-surgery to 18 months post-surgery; however, there was a greater decrease immediately after surgery and then anxiety increased again 18 months later.

The major decrease in state anxiety after surgery can be explained with the immediate relief and decrease in fear after surgery. However, after the operation, many patients have to understand that their cancer treatment is far from over. Increased fear and uncertainties about cancer and its therapy can remain, which explains the increase in state anxiety 18 months after surgery. This is in line with the results of previous studies that found that breast cancer patients have higher levels of psychological distress related to their fear of cancer and its treatment [4, 46-48].

Furthermore, certain aspects of QoL changed over the 18-month period of our study. The patients reported better physical and functional well-being 18 months after the surgery. This change might be partially explained by the decrease in unpleasant physical symptoms and wound healing after surgery and upon completing adjuvant therapy. Adjuvant therapies such as chemotherapy, radiotherapy and hormonal therapy often have severe physical side effects that influence patients' physical and functional wellbeing $[46,49]$. However, a negative relationship was also observed between QoL, depression and anxiety before surgery and 18 months after surgery. In our study, the patients who reported a higher level of psychological distress experienced lower QoL, which is consistent with previous research $[6,50,51]$.

Sociodemographic factors such as age, education level and marital status also influenced QoL. As other studies have suggested, married patients reported better social well-being than patients who were living on their own and patients with a higher level of education reported better QoL [52-56].

In our study, PTG was relatively high among the breast cancer patients. Additionally, age was inversely related to the perception of positive change following cancer. As other researchers have suggested, this type of inverse relationship can be explained by younger patients' potentially experiencing cancer as being more disruptive in their daily life, given that this serious illness is less consistent with their phase of life compared to what it might be like for an older patient $[16,57,58]$.

In our study, patients with lower depression, lower trait anxiety and higher QoL 18 months after the operation reported greater PTG. One explanation for these results might be that a high level of psychological distress experienced before the surgery might have led to illusory instead of real PTG in our sample. Real PTG is a longterm constructive component of personality (perceived new possibilities and increased personal strength). However, for real PTG to appear, an emotional reassessment of the trauma (reduced level of depression and anxiety) is needed [59-61]. In our study, only illusory PTG appeared, as the level of depression did not change over time and state anxiety increased 18 months after surgery. Consistent with previous research, our study highlights that for real PTG to appear, emotional reassessment of the trauma through psychological interventions might play a facilitating role [59-61]. In our study, PTG as an illusory phenomenon served as a short-term coping strategy in reducing the distress produced by the traumatic experience of the operation. In this way, patients, therefore, are able to maintain or defend different aspects of their identity such as selfesteem, coherence and perceived control.

The patients in our sample who had difficulties in association with accepting their changed body image experienced higher levels of depression and trait anxiety 18 months after the surgery. Moreover, patients with severe body image problems experienced lower emotional and physical well-being in our research, highlighting that the trajectories of breast cancer surgery can lead to psychological problems regarding body image, sexuality and femininity. Our findings indicate that, despite the decrease in psychological distress shortly (3 days) after surgery, problems regarding body image can appear and persist 18 months after surgery. An exploration of coping styles, body image perception and social support before surgery might help to identify vulnerable women who can benefit from additional support [31, 62, 63].

In our study, an association between regular physical activity and reduced psychological distress was found 18 months after surgery. As previous research suggested, physical activity can enhance physical and functional wellbeing as well as PTG 18 months after treatment [64, 65]. However, given that this was an observational study, cause and effect cannot be inferred. Although more physically active patients reported greater well-being and PTG 18 months after treatment, there could be many confounders including that those who felt better were able to engage in physical activity.

Linear regression analyses showed that depression and PTG were significant predictors of QoL 18 months after surgery. That is, a lower level of depression and higher perceived PTG were associated with better QoL among the breast cancer patients. These results might have remarkable clinical relevance, as they indicate that psychological interventions following surgery should have a special focus on decreasing psychological distress and enhancing PTG. 
Finally, our study had several limitations. First, the subjects were not representative of the general population in the country. Second, several factors that are potentially associated with depression, anxiety and QoL such as the type of anti-cancer treatment or religiosity were not measured in the study. Awareness of the diagnosis is a factor that is worth investigating in future research, as previous researchers found that it can reduce anxiety and depression [66]. Referring to recent literature, another important factor that affects QoL is family sharing, which has not been evaluated [67]. Finally, the identification of permanent changes in psychological suffering might require a longer period of monitoring and assessment than 18 months. Nevertheless, despite these limitations, our results support the medical relevance of patients' psychological support before and continuously after breast cancer surgery.

\section{Conclusion}

This study showed that overall QoL in breast cancer patients is a multidimensional domain that is influenced by several factors such as psychological distress, PTG, and body image. PTG and the level of depression were found to be factors that potentially contribute to an increase in long-term QoL. In our study, both state and trait anxiety influenced the psychological well-being of the breast cancer patients. Based on our results, a theoretical basis for a future intervention study with breast cancer patients who are undergoing surgery has been created. A focus on the nature of anxiety (current or permanent) and its dynamic changes during the course of an illness might help in the proper management of distress in psychological interventions. Furthermore, we aim to address the great importance of psychological intervention before and after surgery. Psychosocial assessment among breast cancer patients who are undergoing surgery should be multidimensional and simultaneously include an evaluation of long-term QoL, reduction in emotional distress and negative body image and the facilitation of PTG. The overall facilitation of these factors could have a cumulative effect on the healing process in breast cancer patients who are undergoing surgery.

\section{Compliance with Ethical standards}

Conflict of interest The authors declare that they have no conflict of interest.

Ethical approval All procedures performed in studies involving human participants were in accordance with the ethical standards of the institutional and/or national research committee and with the 1964 Helsinki declaration and its later amendments or comparable ethical standards.
Informed consent Informed consent was obtained from all individual participants included in the study.

\section{References}

1. Stewart, B. W., \& Kleihues, P. (2003). World Cancer Report. Lyon: International Agency Research on Cancer.

2. Chida, Y., Hamer, M., Wardle, J., \& Steptoe, A. (2008). Do stress-related psychosocial factors contribute to cancer incidence and survival? Nature Reviews Clinical Oncology, 5, 466-475.

3. Enache, R. G. (2012). The relationship between anxiety, depression and self esteem in women with breast cancer after surgery. Procedia-Social and Behavioral Sciences, 33, 124-127.

4. Schwarz, R., Krauss, O., Hockel, M., Meyer, A., \& Zenger, M. (2008). The course of anxiety and depression in patients with breast cancer and gynecological cancer. Breast Care, 3, 417-422.

5. Vahdaninia, M., Omidvari, S., \& Montazeri, A. (2010). What do predict anxiety and depression in breast cancer patients? A follow-up study. Social Psychiatry and Psychiatric Epidemiology, 45(3), 355-361.

6. Ho, S. S. M., Winnie, K. W. S., Doris, Y. P. L., Eve, T.L. L. \& Carmen, W. H. C. (2013). Anxiety, depression and quality of life in Chinese women with breast cancer during and after treatment: A comparative evaluation. European Journal of Oncology Nursing, 1-6.

7. Holzner, B., Kemmler, G., Kopp, M., Moschen, R., Schweigkofler, H., Dunser, M., et al. (2001). Quality of life in breast cancer patients-not enough attention for long-term survivors? Psychosomatics, 42, 117-123.

8. Dow, K. H., Ferell, B. R., Leigh, S., et al. (1996). An evaluation of the quality of life among long-term survivors of breast cancer. Breast Cancer Research and Treatment, 39, 261-273.

9. Ganz, P. A., Coscarelli, A., \& Fred, C. (1996). Breast cancer survivors: Psychosocial concerns and quality of life. Breast Cancer Research and Treatment, 38, 183-199.

10. Tedeschi, R. G., \& Calhoun, L. G. (1995). Trauma \& transformation: Growing in the aftermath of suffering. Los Angeles, CA: SAGE.

11. Tedeschi, R. G., \& Calhoun, L. G. (2004). Posttraumatic growth: Conceptual foundations and empirical evidence. Psychological Inquiry, 15, 1-18.

12. Antoni, M. H., Lehman, J. M., Kilbourn, K. M., Boyers, A. E., Culver, J. L., Alferi, S. M., \& Carver, C. S. (2001). Cognitivebehavioral stress management intervention decreases the prevalence of depression and enhances benefit finding among women under treatment for early stage breast cancer. Health Psychology, 20, 20-32.

13. Bellizzi, K. M. (2004). Expressions of generativity and posttraumatic growth in adult cancer survivors. International Journal of Aging and Human Development, 58, 247-267.

14. Bellizzi, K. M., \& Blank, T. O. (2006). Predicting posttraumatic growth in breast cancer survivors. Health Psychology, 25, 47-56.

15. Cordova, M. J., Cunningham, L.L.C., Carlson, C. R., \& Andrykowski, M. A. (2001). Posttraumatic growth following breast cancer: A controlled comparison study. Health Psychology, 20, 176-185.

16. Bower, J. E., Meyerowitz, B. E., Desmond, K. A., Bernaards, C. A., Rowland, J. H., \& Ganz, P. A. (2005). Perceptions of positive meaning and vulnerability following breast cancer: Predictors and outcomes among long-term breast cancer survivors. Annals of Behavioral Medicine, 29, 236-245. 
17. Carver, C. S., \& Antoni, M. H. (2004). Finding benefit in breast cancer during the year after diagnosis predicts better adjustment 5-8 years after diagnosis. Health Psychology, 23, 595-598.

18. Tomich, P. L., \& Helgeson, V. S. (2002). Five years later: A cross-sectional comparison of breast cancer survivors with healthy women. Psycho-Oncology, 11, 154-169.

19. Tomich, P. L., \& Helgeson, V. S. (2004). Is finding something good in the bad always good? Benefit finding among women with breast cancer. Health Psychology, 23, 16-23.

20. Park, C. L., Cohen, L. H., \& Murch, R. (1996). Assessment and prediction of stress-related growth. Journal of Personality, 64, 71-105.

21. Updegraff, J. A., \& Taylor, S. E. (2000). From vulnerability to growth: Positive and negative effects of stressful life events. In J. H. Harvey \& E. D. Miller (Eds.), Loss and trauma: General and close relationship perspectives (pp. 3-28). New York: Brunner-Routledge.

22. Bellizzi, K. M., Miller, M. F., Arora, N. K., \& Rowland, J. H. (2007). Positive and negative life changes experienced by survivors of non-Hodgkin's Lymphoma. Annals of Behavioral Medicine, 34, 188-199.

23. Frierson, G.M., Thiel, D.M. \& Andersen, B.L. (2006). Body change stress for women with breast cancer: The Breast-Impact of Treatment Scale. Annals of Behavioral Medicine, 32(1), $77-81$.

24. Shimozuma, K., Ganz, P. A., Petersen, L., \& Hirji, K. (1999). Quality of life in the first year after breast cancer surgery: Rehabilitation needs and patterns of recovery. Breast Cancer Research and Treatment, 56, 45-57.

25. Avis, N. E., Crawford, S., \& Manuel, J. (2004). Psychosocial problems among younger women with breast cancer. PsychoOncology, 13, 295-308.

26. Hong, S., Bardwell, W. A., Natarajan, L., Flatt, S. W., Rock, C. L., Newman, V. A., et al. (2007). Correlates of physical activity level in breast cancer survivors participating in the women's healthy eating and living (WHEL) study. Breast Cancer Research and Treatment, 101(2), 225-232.

27. Dimeo, F. C. (2001). Effects of exercise on cancer-related fatigue. Cancer, 92(6), 1689-1693.

28. Battaglini, C. L., Dennehy, C. A., Groff, D., Kirk, D., \& Anton, P. M. (2006). Complementary therapies in the management of cancer treatment-related symptoms: The individualized prescriptive exercise intervention approach. Medicina Sportiva, 10(2), $49-57$.

29. Courneya, K. S., Friedenreich, C. M., Sela, R. A., Quinney, H. A., Rhodes, R. E., \& Handman, M. (2003). The group psychotherapy and home-based physical exercise (group-hope) trial in cancer survivors: Physical fitness and quality of life outcomes. Psycho-Oncology, 12(4), 357-374.

30. Sabiston, C. M., McDonough, M., \& Crocker, P.R.E. (2007). Psychosocial experiences of breast cancer survivors involved in a dragon boat program: Exploring links to positive psychological growth. Journal of Sport and Exercise Psychology, 29, 419-438.

31. Den Heijer, M., Seynaeve, C., Timman, R., Duivenvoorden, H. J., Vanheusden, K., Tilanus-Linthorst, M., Menke-Pluijmers, M.B.E., \& Tibben, A. (2012). Body image and psychological distress after prophylactic mastectomy and breast reconstruction in genetically predisposed women: A prospective long-term follow-up study. European Journal of Cancer, 48(9), 1263-1268.

32. Alfano, C. M., Smith, A. W., Irwin, M. L., Bowen, D. J., Sorensen, B., Reeve, B. B., et al. (2007). Physical activity, longterm symptoms, and physical health-related quality of life among breast cancer survivors: A prospective analysis. Journal of Cancer Survivorship, 1(2), 116-128.

33. Meisel, J. L., Domchek, S. M., Vonderheide, R. H., GiobbieHurder, A., Lin, N. U., Winer, E. P., \& Partridge, A. H. (2012).
Quality of life in long-term survivors of metastatic breast cancer. Clinical Breast Cancer, 12(2), 119-126.

34. Love, C., \& Sabiston, C. M. (2011). Exploring the links between physical activity and posttraumatic growth in young adult cancer survivors. Psycho-Oncology, 20(3), 278-286.

35. Sackey, H., Sandelin, K., Frisell, J., Wickman, M., \& Brandberg, Y. (2010). Ductal carcinoma in situ of the breast. Longterm follow-up of health-related quality of life, emotional reactions and body image. European Journal of Surgical Oncology (EJSO), 36(8), 756-762.

36. Spielberger, C. D., Gorsuch, R. L., \& Lushene, R. E. (1970). Manual for the state-trait anxiety inventory. Palo Alto: Consulting Psychologists Press.

37. Kopp, M., \& Fóris, N. (1993) A szorongás kognitív viselkedésterápiája. Végeken Sorozat, Budapest.

38. Sipos, K., \& Sipos, M. (1978). The development and validation of the hungarian form of the STAI. In Spielberger, C.D., DiazGuerrero (szerk.): Cross-Cultural Anxiety, 2 (pp. 51-61). Washington-London: Hemisphere Publishing Corporation.

39. Beck, A. T., Ward, C. H., Mendelson, M., et al. (1961). An inventory for measuring depression. Archives of General Psychiatry, 4, 561-571.

40. Eaves, G., \& Rush, A. J. (1984). Cognitive patterns in symptomatic and remitted unipolar major depression. Journal of Abnormal Psychology, 93(1), 31.

41. Rózsa, S., Szádóczky, E., \& Füredi, J. (2001). A Beck Depresszió Kérdõív rövidített változatának jellemzõi a hazai mintán. Psychiatria Hungarica, 16(4), 379-397.

42. Brady, M. J., Cella, D. F., Mo, F., et al. (1997). Reliability and validity of the functional assessment of cancer therapy-breast quality-of-life instrument. Journal of Clinical Oncology, 15, 974-986.

43. Kovács, É., Balog, P., \& Preisz, L. (2012). A Poszttraumás Növekedésérzés Kérdőív pszichometriai mutatói hazai mintán. Mentálhigiéné és Pszichoszomatika, 13(1), 57-84.

44. Frierson, G. M. (2003). The Breast Impact of Treatment Scale: The assessment of body image distress for breast cancer patients. Ohio University.

45. Milne, H. M., Guilfoyle, A., Gordon, S., Wallman, K. E., \& Courneya, K. S. (2007). Personal accounts of exercise and quality of life from the perspective of breast cancer survivors. Quality of Life Research, 16(9), 1473-1481.

46. Taira, N., Shimozuma, K., Shiroiwa, T., Ohsumi, S., Kuroi, K., Saji, S., et al. (2011). Associations among baseline variables, treatment-related factors and healthrelated quality of life 2 years after breast cancer surgery. Breast Cancer Research and Treatment, 128, 735-747.

47. Jadoulle, V., Rokbani, L., Ogez, D., Maccioni, J., Lories, G., Bruchon-Schweitzer, M., et al. (2006). Coping and adapting to breast cancer: A six-month prospective study. Bulletin du Cancer, 93, 67-72.

48. Bárez, M., Blasco, T., Fernández-Castro, J., \& Viladrich, C. (2009). Perceived control and psychological distress in women with breast cancer: A longitudinal study. Journal of Behavioral Medicine, 32, 187-196.

49. Ganz, P. A., Guadagnoli, E., Landrum, M. B., Lash, T. L., Rakowski, W., \& Silliman, R. A. (2003). Breast cancer in older women: Quality of life and psychosocial adjustment in the 15 months after diagnosis. Journal of Clinical Oncology, 21(21), 4027-4033.

50. Ng, C. G., Mohamed, S., See, M. H., Harun, F., Dahlui, M., Sulaiman, A. H., Zainal, N. Z., Taib, N. A. (2015). Anxiety, depression, perceived social support and quality of life in Malaysian breast cancer patients: A 1-year prospective study. Health and Quality of Life Outcomes, 13, 205. 
51. Lidgren, M., Wilking, N., Jönsson, B., \& Rehnberg, C. (2007). Health related quality of life in different states of breast cancer. Quality of Life Research, 16(6), 1073-1081.

52. Tominaga, K., Andow, J., Koyama, Y., Numao, S., Kurokawa, E., Ojima, M., \& Nagai, M. (1998). Family environment, hobbies and habits as psychosocial predictors of survival for surgically treated patients with breast cancer. Japanese Journal of Clinical Oncology, 28(1), 36-41.

53. Cordova, M. J., Giese-Davis, J., Golant, M., Kronenwetter, C., Chang, V., \& Spiegel, D. (2007). Breast cancer as trauma: posttraumatic stress and posttraumatic growth. Psychological Medicine, 14, 308-319.

54. Brix, S. A., Bidstrup, P. E., Christensen, J., Rottmann, N., Olsen, A., Tjønneland, A., Johansen, C., \& Dalton, S. O. (2013). Posttraumatic growth among elderly women with breast cancer compared to breast cancer-free women. Acta Oncologica, 52(2), 345-354.

55. Kucukkaya, P. G. (2010). An exploratory study of positive life changes in Turkish women diagnosed with breast cancer. European Journal of Oncology Nursing, 14, 166-173.

56. King, M. T., Kenny, P., Shiell, A., Hall, J., \& Boyages, J. (2000). Quality of life three months and one year after first treatment for early stage breast cancer: influence of treatment and patient characteristics. Quality of Life Research, 9(7), 789-800.

57. Lechner, S. C., Zakowski, S. G., Antoni, M. H., Greenhawt, M., Block, K., \& Block, P. (2003). Do sociodemographic and disease-related variables influence benefit-finding in cancer patients? Psycho-Oncology, 12, 491-499.

58. Manne, S., Ostroff, J., \& Winkel, G. (2004). Posttraumatic growth after breast cancer: Patient, partner, and couple perspectives. Psychosomatic Medicine, 66, 442-454.

59. Sumalla, E. C., Ochoa, C., Blanco, I. (2009). Posttraumatic growth in cancer: Reality or illusion? Clinical Psychology Review, 29(1), 24-33.
60. Tedeschi, R. G., Park, C. L., \& Calhoun, L. G. (1998). Posttraumatic growth: Positive changes in the aftermath of crisis. Mahwah, NJ: Lawrence Erlbaum.

61. Wagner, B., Forstmeier, S., \& Maercker, A. (2007). Posttraumatic growth as a cognitive process with behavioral components: A commentary on Hobfoll et al. (2007). Applied Psychology, 56, 407-416.

62. Lloyd, S. M., Watson, M., Oaker, G., et al. (2000). Understanding the experience of prophylactic bilateral mastectomy: A qualitative study of ten women. Psycho-oncology, 9(6), 473-485.

63. Hatcher, M. B., Fallowfield, L., \& A'Hern, R. (2001). The psychosocial impact of bilateral prophylactic mastectomy: prospective study using questionnaires and semistructured interviews. British Medical Journal, 322(7278), 76.

64. Cheema, B. S., \& Gaul, C. A. (2006). Full-body exercise training improves fitness and quality of life in survivors of breast cancer. The Journal of Strength and Conditioning Research, 20(1), 14-21.

65. Hefferon, K., Grealy, M., \& Mutrie, N. (2008). The perceived influence of an exercise class intervention on the process and outcomes of post-traumatic growth. Mental Health and Physical Activity, 1, 32-39.

66. Lai, C., Luciani, M., Galli, F., Morelli, E., Del Prete, F., Ginobbi, P., Penco, I., Aceto. P. \& Lombardo, L. (2016). Spirituality and awareness of diagnoses in terminally Ill patients with cancer. The American Journal of Hospice and Palliative Care. doi:10.1177/1049909116630985

67. Lai, C., Borrelli, B., Ciurluini, P., \& Aceto, P. (2016). Sharing information about cancer with one's family is associated with improved quality of life. Psycho-Oncology. doi:10.1002/ pon. 4334 